\title{
Carboxylated Nitrile Butadiene Rubber/Hybrid Filler Composites
}

\author{
Ahmad Mousa $^{\mathrm{a}, \mathrm{b} *}$, Gert Heinrich ${ }^{\mathrm{b}, \mathrm{c}}$, Frank Simon ${ }^{\mathrm{b}}$, Udo Wagenknecht ${ }^{\mathrm{b}}$, \\ Klaus-Werner Stöckelhuber ${ }^{\mathrm{b}}$, Radwan Dweiri ${ }^{\mathrm{a}}$ \\ ${ }^{a}$ Department of Materials Engineering, Faculty of Engineering, \\ Al Balqa Applied University - BAU, Salt 19117, Jordan \\ ${ }^{\mathrm{b}}$ Leibniz-Institut für Polymerforschung Dresden e. V., Hohe Strasse 6, D-01069 Dresden, Germany \\ 'Institute Materials Science, Technische Universität Dresden, Dresden, Germany
}

Received: August 27, 2011; Revised: May 18, 2012

\begin{abstract}
The surface properties of the OSW and NLS are measured with the dynamic contact-angle technique. The X-ray photoelectron spectroscopy (XPS) of the OSW reveals that the OSW possesses various reactive functional groups namely hydroxyl groups $(\mathrm{OH})$. Hybrid filler from NLS and OSW were incorporated into carboxylated nitrile rubber (XNBR) to produce XNBR hybrid composites. The reaction of $\mathrm{OH}$ groups from the OSW with $\mathrm{COOH}$ of the XNBR is checked by attenuated total reflectance spectra (ATR-IR) of the composites. The degree of curing $\Delta M$ (maximum torque-minimum torque) as a function of hybrid filler as derived from moving die rheometer (MDR) is reported. The stress-strain behavior of the hybrid composites as well as the dynamic mechanical thermal analysis (DMTA) is studied. Bonding quality and dispersion of the hybrid filler with and in XNBR are examined using scanning-transmission electron microscopy (STEM in SEM).
\end{abstract}

Keywords: olive solid waste, environment, strength, hybrid filler, composite, elastomer

\section{Introduction}

Carboxylated nitrile rubber (XNBR) is a modified NBR with carboxylic groups along the hydrocarbon backbone ${ }^{1}$. $\mathrm{XNBR}$ is polar, reactive polymer that exhibits good compatibility with polar or non-polar resins and higher degree of interaction with fillers ${ }^{2}$. It is also reported that XNBR has improved damping properties, showing a great potential as matrix polymers ${ }^{3,4}$. Since polymer are rarely used commercially in a pure state to modify some of their properties by the incorporation of various additives, such as fillers, vulcanizing agents, and plasticizers etc. However, until now few reports have been made on the use of XNBR employed as matrix polymer in landfill organic fillers hybrid systems. The organic landfill fillers emerge from renewable resources that are normally naturally occurring biomaterials of woody nature and are gaining attention due to economical and ecological reasons. Examples on this type are but not limited to rice husk, sisal, jute etc. The naturally occurring materials have many advantages such as easy processability, environmental friendly, low cost and reduced wear on the processing machine ${ }^{5,6}$. One of the most common agrowaste materials is olive husk powder that is lingocellulosic material produced by the olive oil industry. Annually thousands of tones of such material are thrown in the landfills as solid waste materials. In a previous investigations we studied the effect of unmodified OSW in toughened and rigid PVC consequently ${ }^{7,8}$. We found that the addition of OSW offers the possibility of improving tensile and flexural modulus of the wood-like composites by varying the filling level. It

*email: mousa@ rocketmail.com has been realized that the polarity of the matrix is crucial factor in judging the compatibility between the agro polymer and the synthetic counterpart; this situation may disrupt the importance of economy posed by agro polymers. To enhance the value of this material without the use of coupling agents we incorporated it into polar polymer such as XNBR. The potential of OSW on the cure characteristics and mechanical properties of XNBR vulcanizate has been reported ${ }^{9,10}$. In these reports we showed that the agro polymer based OSW was able to reinforce the XNBR vulcanizate which permit the usage of such materials without using compatibilizers but the eye was kept open on further improvement of the performance of the composites without chemical modification of the filler. From various studies on nano composites, the incorporation of the nano filler into polymer matrix increases the strength as well as the modulus of the composites $^{11-16}$. The high surface area and aspect ratio of the nano filler makes it suitable candidate to balance the adverse effect of the irregularities of the lignocellulosic fillers. Keeping in mind that NLS is polar material with organic component, simultaneously the OSW is polar and organic with various functional groups as displayed by the XPS data. Interestingly, both NLS and OSW were found to have more or less similar surface tension. It is believed that both of them are capable to reinforce the polar XNBR while the NLS will mitigate any short coming from the agro polymer, while the OSW as a cheap material will balance the economy. The potential of the polar binary filler on the mechanical, morphological and dynamic mechanical properties of the polar XNBR vulcanizate is reported. 


\section{Experimental}

\subsection{Materials}

Carboxylated nitrile rubber used in this study was obtained from LANXESS, Germany [Krynac 740, ML $1+4 @ 100{ }^{\circ} \mathrm{C}$ is $38 \pm 4$, acrylonitrile content 26.5, carboxylic acid content 7\%]. Quaternary ammonium salt modified natural Montmorillonite; Nanofil 15 donated by Süd-chemie AG, Germany. ACROS Organics, Belgium, supplied stearic acid and zinc oxide powder. Mercapto Benzo-thiazole Sulfinamide (MBTS) and sulfur were used as vulcanizing system. The olive solid waste (OSW) was obtained from a local olive refinery in Jordan, the particle size of which was $\leq 45 \mu \mathrm{m}$. The process of the OSW treatment was reported in our previous works ${ }^{8-10}$.

\subsection{Formulation and sample fabrication}

The recipe used to produce the rubber hybrid composites based on $100 \mathrm{phr}$ XNBR is shown in Table 1. Three formulations were prepared in this work these are: The control, which is XNBR vulcanizate and designated as C; the control with organo-nanosilicates and designated as CS; and the control with hybrid filler being designated as $\mathrm{CH}$. The samples were fabricated by Brabender two roll mill (C.W. Brabender instruments, Hackensack, NJ; $230 \mathrm{~V}, 40 \mathrm{~A}$ ) at room temperature and $25 \mathrm{rpm}$ for 10 minutes. The state of cure, which is indication of the crosslink density, was determined using an Ekktron oscillating disc rheometer at $160{ }^{\circ} \mathrm{C}, 1.66 \mathrm{~Hz}$ frequency and 0.5 arcs. Rectangular sheets of $2 \mathrm{~mm}$ thickness were molded at $10 \mathrm{MPa}$ and $160^{\circ} \mathrm{C}$ using Carver Auto Series compression molding machine according to their $\mathrm{t}_{90}$ as derived from Ekktron moving die rheometer.

\subsection{Surface energy determination of fillers}

The advancing and receding contact angle of the OSW and organo NLS particles was determined according to Wilhelmy plate method. The measurements were carried out on Data Physics DCAT 21 Tensiometer (Filderstadt, Germany). The sample container was cleaned with distilled water and then dried in oven. The surface energies of the OSW and the organo NLS were calculated from the wetting data using a series of test liquids with different surface tension: Water (Millipore Milli-Q-Quality), Formamide (Merck, Darmstadt, Germany), ethyleneglycol (Fisher Scientific, Loughborough, UK), dodecane (Merck Schuchardt, Hohenbrunn, Germany), hexadecane (Merck, Darmstadt, Germany), ethanol (Uvasol, Merck, Darmstadt, Germany) and mixtures of ethyleneglycol (EG) or ethanol respectively with water. The test fluid was filled into the container and the temperature was maintained at $20{ }^{\circ} \mathrm{C}$ before each measurement. The particles were first adhered

Table 1. Recipe used to produce XNBR hybrid composites based on 100 phr*.

\begin{tabular}{ccccccc}
\hline XNBR & $\begin{array}{c}\text { Stearic } \\
\text { acid }\end{array}$ & $\begin{array}{c}\text { zinc } \\
\text { oxide }\end{array}$ & MBT & Sulfur & NLS & $\begin{array}{c}\text { NLS/ } \\
\text { OSW }\end{array}$ \\
\hline 100 & 1 & 3 & 0.7 & 1.5 & 5 & $5 / 15$ \\
\hline
\end{tabular}

*phr is part per hundred part rubber. on an adhesive tape (TESA 55733, Beiersdorf Germany) and the loosely held particles were blown away by a stream of nitrogen. The particles adhered on tape surface were used for Wilhelmy contact angle measurements. To carry out the measurements the tape was fixed into the tensiometer holder and immersed into the test liquid and the resulting advancing and receding contact angle values were recorded. Fowkes equation was used to find out the value of the dispersive component and the polar component ${ }^{17}$.

\subsection{Dynamic mechanical thermal analysis (DMTA)}

The complex modulus ( $\left.\mathrm{E}^{*}\right)$, its storage ( $\left.\mathrm{E}^{\prime}\right)$, loss ( $\left.\mathrm{E}^{\prime \prime}\right)$, and the mechanical loss factor $(\tan \delta)$ as a function of temperature, were assessed by DMTA using an Eplexor 2000N DMTA (version $8.373 \mathrm{~h}$ ) Germany in tension mode on rectangular specimens. The samples were scanned as a function of temperature from -40 to $100{ }^{\circ} \mathrm{C}$ at heating rate of $3{ }^{\circ} \mathrm{C} / \mathrm{min}$ and constant frequency of $10 \mathrm{~Hz}$. The static load strain was $1 \%$ and dynamic load strain was $0.5 \%$.

\subsection{Tensile properties}

Tensile tests were performed on $2 \mathrm{~mm}$ thick dumbbells at ambient temperature on a Zwick 1456 universal testing machine at a deformation rate of $500 \mathrm{~mm} / \mathrm{min}$ according to ASTM D412/S2/500. The dumbbell specimens were cut from molded rubber sheets. Five specimens were tested and the median value was taken for each formulation.

\subsection{STEM}

Thin sections for scanning transmission electron microscopy analysis were microtomed at $-130{ }^{\circ} \mathrm{C}$. The sections were examined by scanning electron microscope model Ultra plus (Carl Zeiss NTS) coupled with STEM detector.

\subsubsection{X-ray photon spectroscopy}

The chemical composition of the OSW was determined using the XPS technique using the AXIS ULTRA spectrometer (Kratos Analytical, England). The $\mathrm{X}$-Ray-source was Mono-Al $\mathrm{K} \alpha_{1,2}$, power of the $\mathrm{X}$-ray source: $300 \mathrm{~W}$ at $20 \mathrm{~mA}$. Spectra were recorded with pass energy of $160 \mathrm{eV}$. For each sample, a detailed scan of the $\mathrm{O} 1 \mathrm{~s}, \mathrm{C} 1 \mathrm{~s}, \mathrm{~N} 1 \mathrm{~s}$, and $\mathrm{Si} 2 \mathrm{p}$ lines was performed with pass energy of $20 \mathrm{eV}$. The calibration of the binding energy (BE) scale was made by setting the $\mathrm{C} 1 \mathrm{~s} \mathrm{BE}$ of the neutral carbon (C-C and $\mathrm{C}-\mathrm{H}$ bonds) peak.

\section{Results and Discussions}

\subsection{X-ray photon spectroscopy}

The sample showed the following elements as presented in Figure 1a, carbon ${ }^{6}$ as $\mathrm{C}$ 1s peak, nitrogen ${ }^{7}$ as $\mathrm{N}$ 1s peak, oxygen $^{8}$ as $\mathrm{O} 1 \mathrm{~s}, \mathrm{O} 2 \mathrm{~s}, \mathrm{O} \mathrm{KL} 1=\mathrm{O} \mathrm{KL}_{23} \mathrm{~L}_{23}, \mathrm{O} \mathrm{KL} 2=\mathrm{O} \mathrm{KL}_{1} \mathrm{~L}_{23}$ and $\mathrm{O} K \mathrm{KL} 3=\mathrm{OKL} \mathrm{L}_{1}$ peaks, aluminium ${ }^{13}$ as $\mathrm{Al} 2 \mathrm{p}_{3 / 2}$, $\mathrm{Al} 2 \mathrm{p}_{1 / 2}$ and $\mathrm{Al} 2 \mathrm{~s}$ peaks, silicon ${ }^{14}$ as $\mathrm{Si} 2 \mathrm{p}_{3 / 2}, \mathrm{Si} 2 \mathrm{p}_{1 / 2}$ and $\mathrm{Si} 2 \mathrm{~s}$ peaks, calcium ${ }^{20}$ as $\mathrm{Ca} 2 \mathrm{p}_{3 / 2}, \mathrm{Ca} 2 \mathrm{p}_{1 / 2}, \mathrm{Ca} 2 \mathrm{~s}$ and $\mathrm{Ca} 3 \mathrm{~s}$ peaks. The wide-scan and high-resolution $\mathrm{C} 1 \mathrm{~s}$ XPS spectra of the OSW is shown in Figure 1b. The C 1s spectrum does not 


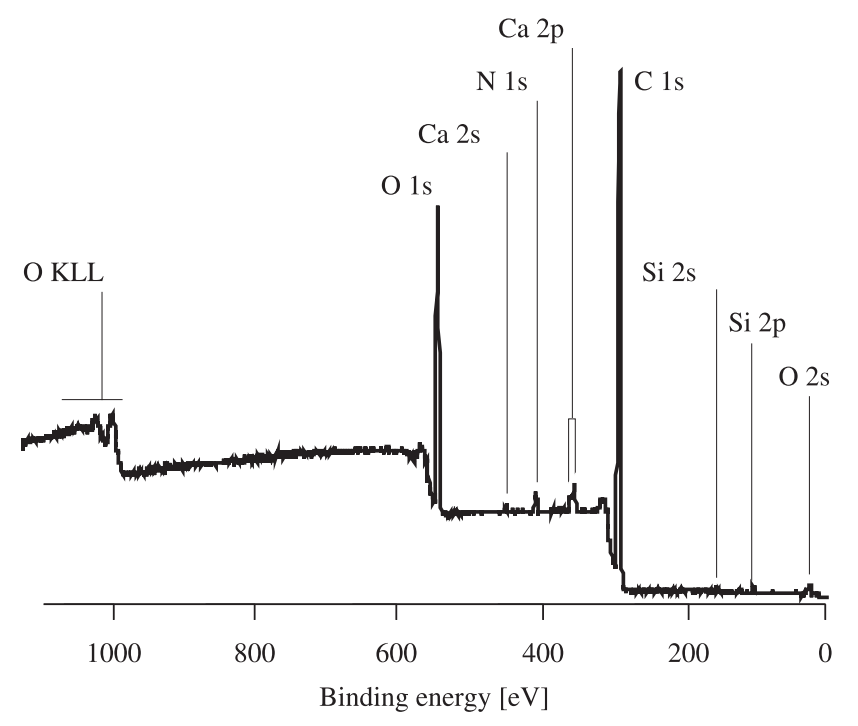

(a)

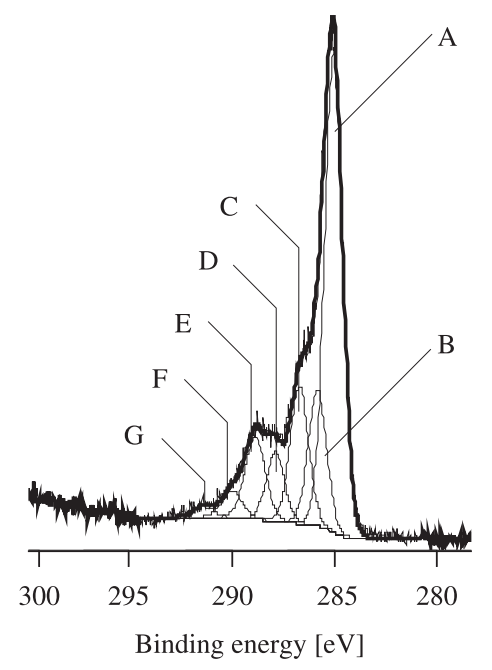

(b)

Figure 1. Wide-scan and high-resolution C 1s XPS spectra of olive residual sample.

show the typical shape of a spectrum, which was recorded from a cellulose material. The spectrum was deconvoluted into seven component peaks $(A, B, C, \ldots, G)$ showing the different binding states of carbon. Component peak $A$ appears from saturated hydrocarbons $\left(\mathrm{C}_{\mathrm{x}} \mathrm{H}_{\mathrm{y}}\right)$. Component peak $C$ shows $\mathrm{C}-\mathrm{OH}$ groups from the cellulose material and alcoholic/phenolic $\mathrm{C}-\mathrm{OH}$ groups. The alcohol-side carbon of ester groups $(\mathrm{O}=\mathrm{C}-\mathrm{O}-\mathrm{C})$ also contribute to this component peak. Component peak $D$ results from the acetal group $(\mathrm{O}-\mathrm{C}-\mathrm{O})$ of the polysaccharides and keto groups $(\mathrm{C}=\mathrm{O})$. If it is assumed that all carbon atoms contributing to component peak $C$ are components of the polysaccharide molecules, the intensity of component peak $D$ should be $1 / 5$ of the intensity of component peak $D$. Clearly it can be seen that other components, like $\mathrm{C}=\mathrm{O}$ bonds of keto groups mainly contribute to component peak $D$. Component peak $E$ shows ester $(\mathrm{O}=\mathrm{C}-\mathrm{O}-\mathrm{C})$ as well amide $(\mathrm{O}=\mathrm{C}-\mathrm{NH}-\mathrm{C})$ or peptide groups. Carbonic acids $(\mathrm{O}=\mathrm{C}-\mathrm{OH})$ contribute to component peak $F$. Component peak $G$ appears from inorganic carbonate $\left(\mathrm{CO}_{3}{ }^{2-}\right)$ or/and hydrogen carbonate $\left(\mathrm{HCO}_{3}^{-}\right)$groups. Its share area equals the $\left.[\mathrm{Ca}]:[\mathrm{C}]\right]_{\text {spec }}$ ratio determined from the wide-scan spectrum. Hence, it can be assumed that calcium is present as $\mathrm{CaCO}_{3}$ in the sample. Component peak $B$ shows $\mathrm{C}-\mathrm{N}$ appearing from amines and amide bonds $(\mathrm{O}=\mathrm{C}-\mathrm{NH}-\mathrm{C})$. Carbon atom are situated in the neighbourhood ( $\alpha$-position) of the strongly electronegative carbonic acid or ester/amide groups also contributes to component peak $B$. Thus, it can be anticipated that this agro polymer is of surface polar nature.

\subsection{Mechanical properties}

Figure 2a compares the influence of single and hybrid filler on the tensile strength at break of XNBR composites compared to the gum vulcanizate. It can be seen that the addition of the layered nanosilicates increases the tensile strength at break of the XNBR composite. The reinforcement efficiency of organoclay may be attributed to the strong interaction between organoclay and XNBR. The smaller particle size provides a larger surface area for the interaction between the filler and rubber matrix. Further more, the better tensile strength of organoclay could be due to its high aspect ratio and platelet structure. The effect of the OSW filler on the tensile strength at break of the XNBR-NLS composite is shown in Figure 2a as well. It is obvious that the addition of OSW to the XNBR-NLS had further increased the tensile strength of the composite compared to the plain counterpart not only this but also exceeds that of the organoclay filled composite. Such observation should be traced to two main reasons: firstly, the interactions between the filler and the matrix, secondly the dispersion of the filler within the matrix. Recall that OSW as a lignocellulosic material is capable of interaction with the XNBR matrix. In line with tensile strength course the tensile modulus of the composite with single and hybrid filler is shown in Figure 2a as well. It is noticed that tensile modulus of the composite with NLS has been increased which is also an indicator on increased stiffness. The addition of the OSW to the XNB-NLS composite displayed higher values of the tensile modulus compared to the control and the composite with NLS. The increased stiffness is related to the fact that stiffness or modulus is affected by surface reactivity of fillers, particle size, and filler-rubber interaction. For NLS the filler-rubber interaction is stronger. It also can be attributed to the high surface area of NLS, which allows better interaction with the rubber matrix, thus the reinforcing efficiency is improved. These characteristics may be suitable for a single-filler system where the only interaction is between the NLS filler and neat polymer. However, with the incorporation of OSW filler, the combined interaction of both fillers with the matrix has positively affected the tensile modulus. Figure $2 \mathrm{a}$ also illustrates the influence of filler on the $\%$ elongation at break of the vulcanizate. Organoclay 


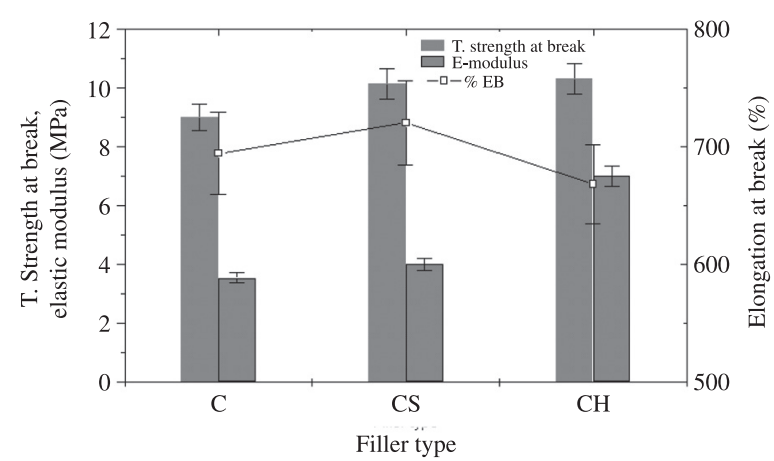

(a)

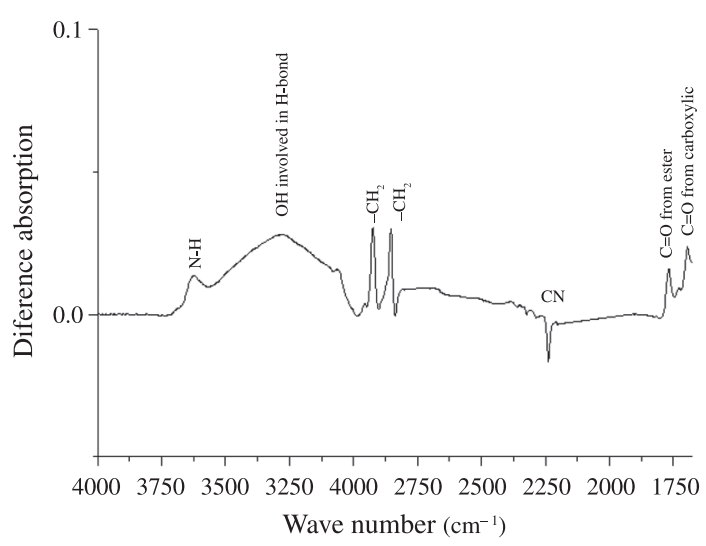

(b)

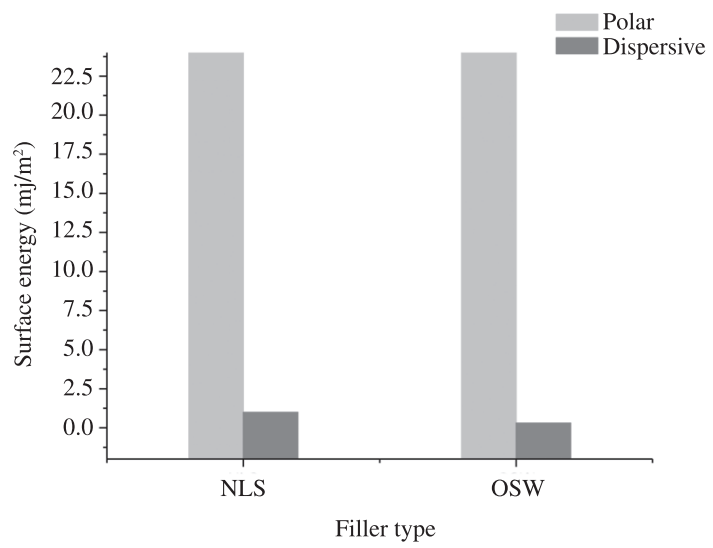

(c)

Figure 2. a) Tensile properties of XNBR composites; b) ATR-IR difference spectra of XNBR composites; c) surface energy.

shows higher elongation at break than XNBR gum vulcanizate which is in line with earlier report on $\mathrm{SBR} /$ organoclay ${ }^{13}$. This is believed to be related to two main reasons the former is the intercalated/exfoliated structure of the nanosilicates, which allows an easy reorientation of the platelets. The latter is the lubricating role acted by the platy nanoclay that will enhance the molecular retractability of network. In the case of the combined filler, it is clear that the addition of the OSW has deteriorated the \%EB of the composites compared to the organoclay shown in Figure 2a. The loss in \%EB is due to the relatively high concentration of the filler (20 phr). Therefore, the free volume of the matrix will decrease, rigidity and stiffness increased, hence strong interaction between the matrix and the two types of filler is expected to reduce the extensibility of the composite. The possible interactions between the single and hybrid filler was evaluated using difference ATR-IR spectra (the spectrum of $\mathrm{CH}$ formula - the spectrum of $\mathrm{C}$ formula) is presented in Figure 2b. Recall that absorption above the base line indicates the formation of new species or the increment in concentration of existing ones, whereas the absorption below the base line indicates decrease of existing ones. Thus, the interaction between the matrix and the hybrid filler can be evidenced from the formation of ester carbonyl peak at $1770 \mathrm{~cm}^{-1}$ due to the reaction of $\mathrm{OH}$ groups from the OSW with $\mathrm{COOH}$ of the XNBR. On the other hand the dipole-dipole interactions are confirmed in Figure $2 b$ as well, the related absorption is the carboxylic acid at $1690-1725 \mathrm{~cm}^{-1}$ and the absorption at $3627 \mathrm{~cm}^{-1}$ related the $\mathrm{N}-\mathrm{H}$ from the $\mathrm{N}$ of the quaternary ammonium salt of the NLS and the proton of hydroxyl group involved in $\mathrm{H}$-bond, one more significant peak at $3275 \mathrm{~cm}^{-1}$ that is related to the $\mathrm{OH}$ involved in $\mathrm{H}$-bond. It is worth mentioning that we observed that the XNBR vulcanizate reinforced OSW showed only H-bond formation without any ester formation ${ }^{7}$. The formation of ester was detected in the presence of NLS as shown in the current work. Regarding the dispersion of the filler into the matrix, the surface energy of the solid filler particles are presented in Figure 2c. It is obvious that the OSW and the NLS are of similar surface energy (polar and dispersive part). Thus, it can be inferred that the single or the combined filler system were compatible with the XNBR due to the polar-polar interactions between the three components. This is expected to increase the work of adhesion between the NLS and the OSW. In the presence of the binary reinforcement the work of adhesion will be of dual effect. To further support the claim of enhanced rubber-filler interactions, the degree of crosslinking evaluated as $\Delta M$ derived from MDR of all mixtures studied is presented in Figure 3. It can be seen that the addition of the nanosilicates has increased the state of cure i.e. the crosslink density compared to the control sample. In addition 
to the greater rubber-NLS interaction as mentioned earlier, the quaternary ammonium compound within the NLS is expected to facilitate the sulfur curing reaction via the formation of transition complex between the amine and sulfur which increased the extent of cure. This is in line with earlier work on other rubber systems ${ }^{13}$. The incorporation of the OSW to the XNB-NLS composite has further increased the extent of cure. Again, this is attributable to the amine functionality within the OSW to promote the sulfur curing reaction. The amine functionality posed form $\mathrm{C}-\mathrm{N}$ appearing from amines and amide bonds $(\mathrm{O}=\mathrm{C}-\mathrm{NH}-\mathrm{C})$ or peptide groups as shown by the XPS data in Figure 1. One should not oversight the polar-polar interaction as well as the formation of ester linkage mentioned earlier. Hence, it can be concluded that the OSW and NLS could act as co-curing agents beside their reinforcing abilities. Note that swelling index data presented in Figure 3 is opposite to the degree of crosslinking $(\Delta M)$ data. Recall that swelling index is inversely related to the crosslink density. The OSW containing composite shows the lowest value of swelling index, followed by the NLS and the XNBR gum. The indication is that the stiffer the composite is the less solvent penetrable is the compound. This conclusively proves that the incorporation of agro polymer in the NLS composite has facilitated the formation of new crosslinks. The conclusion is that besides the sulfur crosslinks initiated by the sulfur curing system the active functional groups of the fillers were capable to form primary and secondary physical bonds between the fillers and the matrix. The formation of physical crosslinks is well reflected in $\alpha$ transition of the $\tan \delta$ curve shown in Figure 4 . The second transition $(\alpha)$ is seen in the range of 40 to $100{ }^{\circ} \mathrm{C}$. This transition became more distinct after the incorporation of the OSW agro polymer. Also, it is interesting to note that $\alpha$ transition temperature was shifted to higher temperatures as well. Figure 5 depicts the hardness dependence of XNBR composite on the filler type. Note that the incorporation of the NLS has increased the hardness of the composite. This should be due to the volume fraction reduction of the matrix after the addition of the silicates in addition to the increased

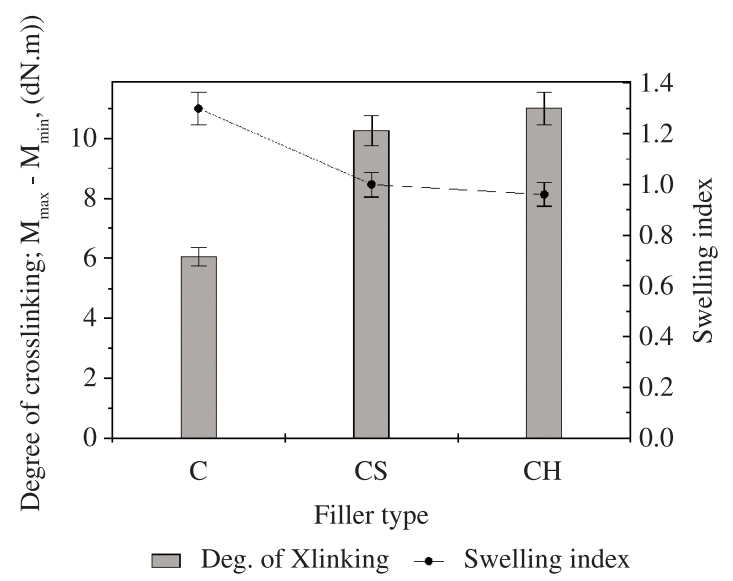

Figure 3. Swelling Index and degree of cross link of XNBR vulcanizte and it's composites. strength of the whole composite after the intercalation/exfoliation of NLS. The addition of the OSW filler has further increased the hardness because of the further reduction in the volume fraction of the matrix upon the addition of the hybrid filler as well as the increased degree of interaction between the OSW and the XNBR-NLS.

\subsection{DMA}

The dynamic storage modulus of gum XNBR and the composites as a function of temperature is shown in Figure 6. All the composites show higher storage modulus than the gum vulcanizate over the entire temperature range; the order of fillers, corresponding to the stiffness at the whole temperature range, is the NLS/OSW $>$ NLS $>$ gum. At higher temperature (beyond $\mathrm{T}_{\mathrm{g}}$ ) one should not forget that the inorganic nature of the NLS will absorb some of the heat which retards the softening of the composite as compared to the gum vulcanizate. Note that at higher temperature the addition of the OSW increased E' which is a hint on the ability of the OSW to enhance the thermal stability of the XNBR-NLS composite. This is attributable to the improved degree of interaction between the OSW and the XNBR-NLS composite besides the role of lignin phenolic hydroxyl group of the OSW acting as antioxidant could explain such behavior. Figure 4 shows the variation of $\tan \delta$ with temperature for the gum vulcanizate and the

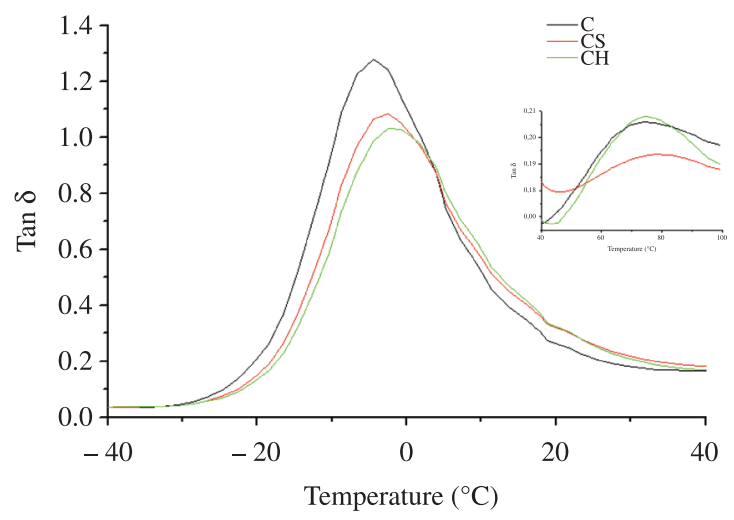

Figure 4. The influence of Filler Type on $\tan \delta$ of XNBR composites.

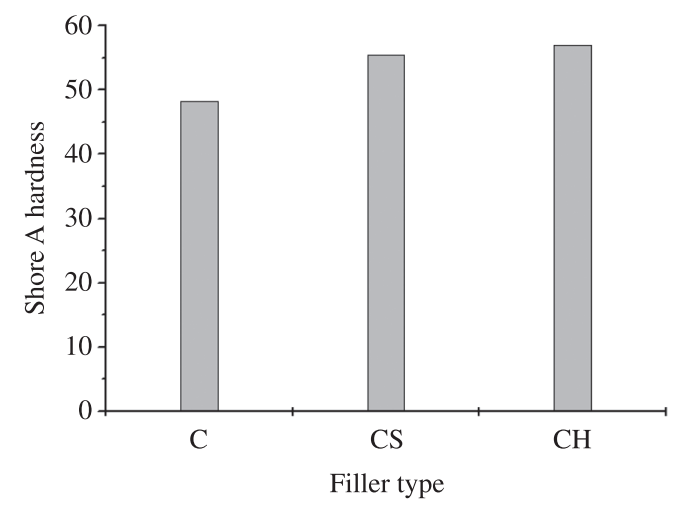

Figure 5. The effect of filler type on the shore A hardness of the XNBR composites. 
composites. Figure 4 indicates that the incorporation of the NLS has delayed the onset of micro-Brownian motion of the composites compared to the gum vulcanizate. In the glass transition region, damping is high due to the onset of micro-Brownian motion within the molecular structure of the main chain, and so is the $\tan \delta$. Breaking intermolecular bonds allows greater chain mobility and results in a decrease of $\boldsymbol{T g}$ as well as an increase in magnitude of $\tan \delta$ Keeping this in mind the curve shows different $\tan \delta$ peak heights. The ranking of the $\tan \delta$ heights was; gum $>$ NLS > OSW/NLS; which is opposite to the trend of the Tg values for the

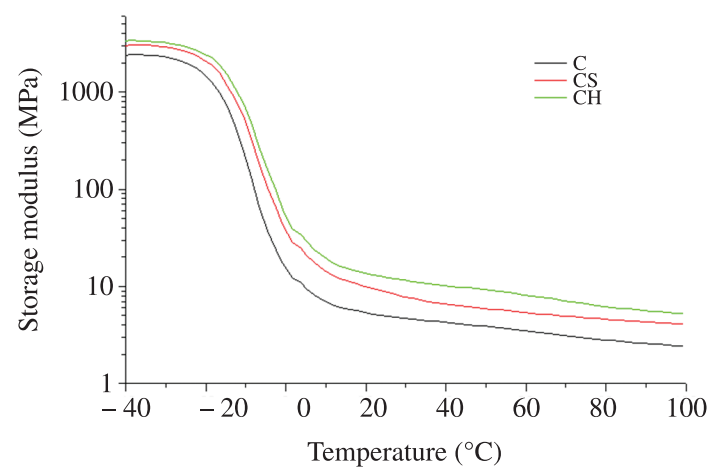

Figure 6. The influence of filler type on E` of XNBR composites.

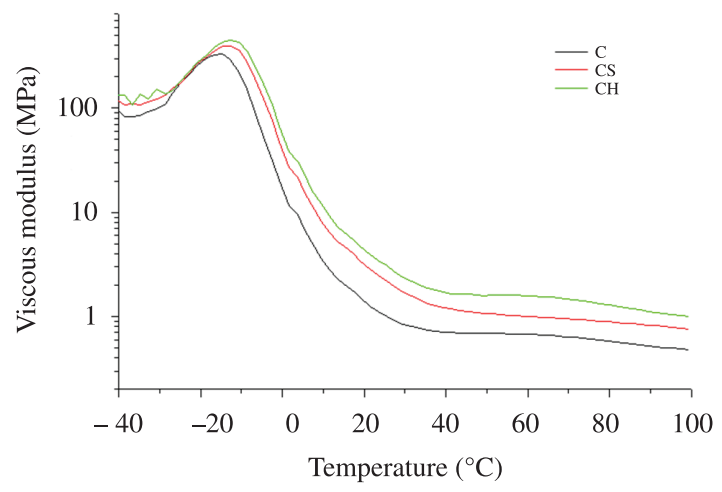

Figure 7. The influence of filler type on E“" of XNBR composites.

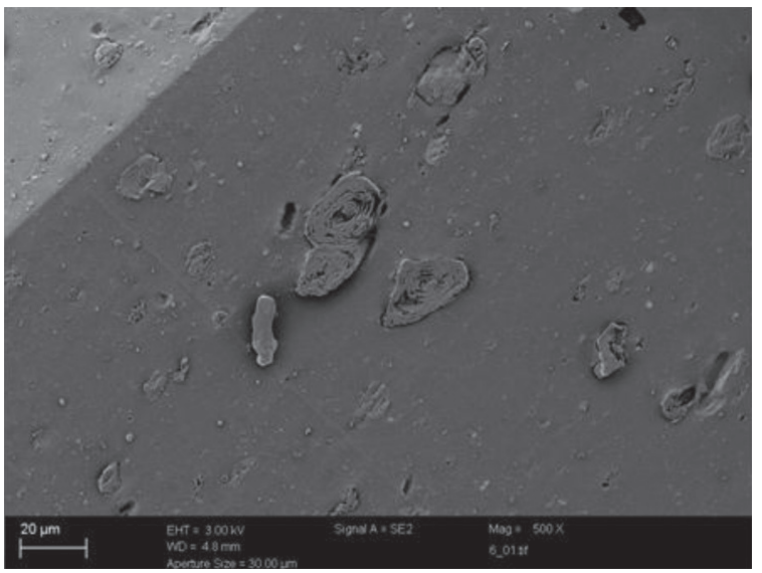

(a) same formulas i.e. OSW/NLS $>$ NLS $>$ gum. This is due to the interaction between the NLS and the XNBR matrix as the molecular relaxation of the latter is hindered. The incorporation of the OSW into the NLS filled vulcanizate has further decreased the magnitude of $\tan \delta$ and shifted the $\mathrm{Tg}$ to higher values. This is attributable to the increased degree of interaction between the OSW and the XNBR-NLS composite. It can also be seen that there is a secondary peak observed at $3{ }^{\circ} \mathrm{C}$ for the composites except for the gum vulcanizate. This might be related to the part of the rubber that is intercalated in between the NLS layers. A similar observation was also reported by other researchers ${ }^{18-20}$. Figure 7 shows the loss moduli spectra of the XNBR composites. All composite formulations exhibited higher loss modulus values than that of gum vulcanizate, the ranking of the fillers is, OSW/NLS $>$ NLS $>$ gum. Furthermore, the glass transition temperature derived from the loss modulus data was shifted to higher values, the ranking is gum $<$ NLS $<$ OSW/NLS. The trend observed here is in line with data extracted from the $\tan \delta$ curve. Thus it could be concluded that, the incorporation of agro polymer had improved the damping behavior of the composite properties all over the temperature range, followed by the NLS filled composite with respect to the gum vulcanizate.

\subsection{STEM in SEM}

Cryogenically fractured surface of XNBR-XNBR composite and XNBR-NLS/OSW were inspected using scanning electron microscope coupled with STEM detector. The SEM micrographs related to the thin film cut $(30 \mathrm{~nm}$ at $-130{ }^{\circ} \mathrm{C}$ ) of the NLS and hybrid filled Vulcanizates are depicted in Figure $8 \mathrm{a}$ and $\mathrm{b}$ respectively. The surface of the composite with NLS is smooth with a fairly homogenous polymer composite and minimal stress zones. The NLS particles are well wetted by the matrix without serious agglomeration. On the other hand the fracture surface of the XNBR-NLS composite containing OSW displayed rougher surface where the NLS particles are covered by the matrix. The image revealed that the quality of boning between the OSW and the matrix is firm. This was due to the compatibility between the OSW and XNBR due to

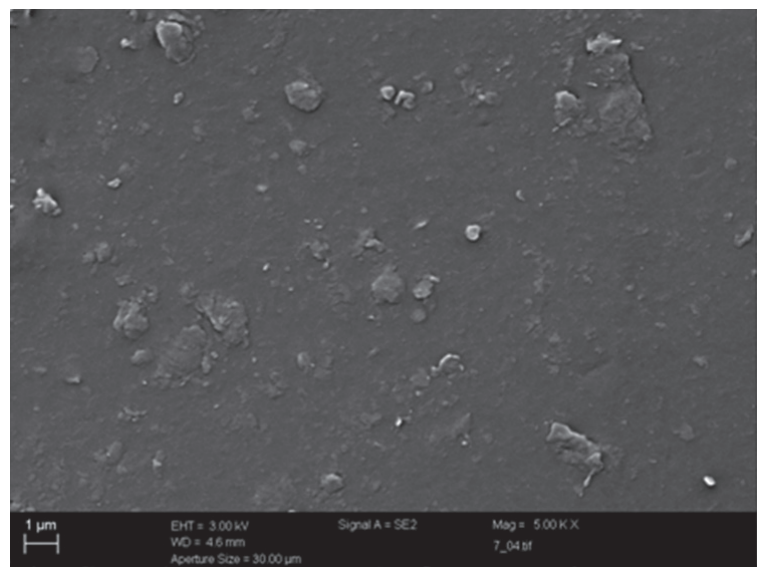

(b)

Figure 8. a) Composite with NLS; b) Composite with hybrid filler. 


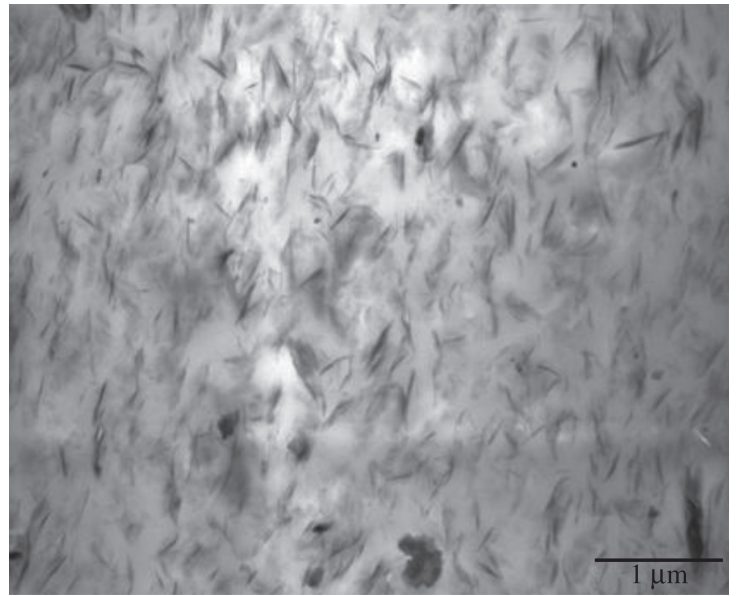

(a)

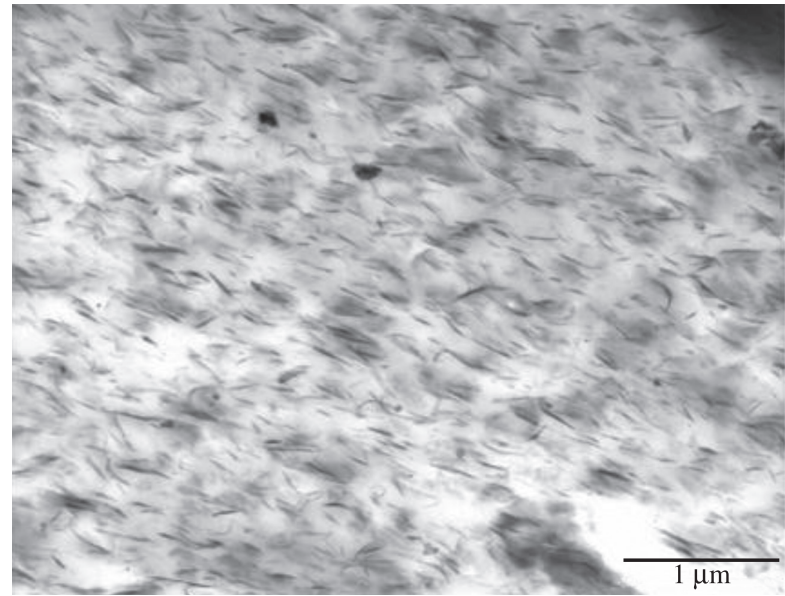

(b)

Figure 9. TEM micrograph of XNBR composite (a) with NLS (b) with hybrid filler.

the matrix-OSW interaction promoted by the polarity of both surfaces. The better degree of boning was reflected by the increase in tensile strength of the composite with hybrid filler. To check out the dispersion state of the NLS the STEM mode of the SEM was operated for the same thin film samples. Figure 9a shows an image of XNBR vulcanizate structure infused with NLS. In this image darker stacked arrangement of lines and random lines are visible against the lighter background. The lines show an ordered stacked arrangement. This suggests that mixed morphologies of exfoliated and intercalated nanostructures with some agglomerates as indicated by the black bundles were achieved. This is why at this low weight loading of NLS, the modulus and strength of XNBR vulcanizate were improved. Figure $9 \mathrm{~b}$ shows TEM image of XNBR-NLS composite reinforced with OSW. It can be seen that the NLS of the hybrid filler had better orientation than the NLS of the single filler reinforced composite. The intercalation/exfoliation is the distinct morphology in this image. The image shows arrangements of stacked lines with some interspaces. This indicates presence of intercalated-exfoliated morphology. The image displayed fewer dark lines or bundles compare to the single filled vulcanizate. These sites indicate agglomerated NLS sites with little penetration by the polymer into the interlayer. The image also revealed some random clay platelets representative of exfoliated morphology.

\section{References}

1. Ibarra L, Rodriguez A and Mora I. Ionic nanocomposites based on XNBR-OMg filled with layered nanoclays. European Polymer Journal. 2007; 43:753-761. http://dx.doi. org/10.1016/j.eurpolymj.2006.12.007

2. Bandyopadhyay S, De PP, Tripathy DK and De SK. Influence of surface oxidation of carbon black on its interaction with nitrile rubbers. Polymer. 1996; 37:353-357. http://dx.doi. org/10.1016/0032-3861(96)81110-4

\section{Conclusions}

Based on the aforementioned results the following conclusions might be drawn:

The incorporation of agro polymer based OSW into the XNBR-NLS composites had improved the mechanical properties compared to XNBR-NLS as well as XNBR gum vulcanizate. This was due the improved degree of interaction via the reaction between the hydroxyl group of OSW and the carboxylic group of the matrix as evidenced by the IR spectra. As such this was reflected by the enhancement of the work of adhesion. The DMA results revealed that the incorporation of the hybrid filler has increased the glass transition temperature of the composite. The increased storage and loss moduli with the decreased mechanical loss factor were indicators on the improved shape memory characteristics of the composites compared to gum vulcanizate. The STEM micrographs revealed good NLS dispersion as indicated by the TEM micrographs, while the quality of bonding between the OSW and the matrix was reasonable as indicated the SEM micrographs one. In conclusion successful hybrid filler was achieved.

\section{Acknowledgements}

Ahmad Mousa is thankful to the Leibniz-Institut für Polymerforschung Dresden e.V., for the research stay from June-August 2009.
3. Manoj NR, Chandrasekhar L, Patri M, Chakraborty $\mathrm{BC}$ and Deb PC. Vibration damping materials based on interpenetrating polymer networks of carboxylated nitrile rubber and poly(methyl methacrylate). Polymers for Advanced Technologies. 2002; 13:644-648. http://dx.doi.org/10.1002/ pat.324

4. Manoj NR, Raut RD, Sivaraman P, Ratna D and Chakraborty BC. Sequential interpenetrating polymer network of poly(ethyl methacrylate) and carboxylated nitrile rubber: Dynamic mechanical analysis and morphology. Journal of 
Applied Polymer Science. 2005; 96:1487-1491. http://dx.doi. org/10.1002/app.21258

5. Karmaker AC and Hinrichsen G. Processing and Characterization of Jute Fiber Reinforced Thermoplastic Polymers. Polymer - Plastics Technology and Engineering. 1991; 30:609-29. http://dx.doi. org/10.1080/03602559108019223

6. Rozman HD, Tan KW, Kumar RN, Abubakar A, Mohd Ishak $\mathrm{ZA}$ and Ismail $\mathrm{H}$. The effect of lignin as a compatibilizer on the physical properties of coconut fiber-polypropylene composites. European Polymer Journal. 2000; 36:1483-94. http://dx.doi. org/10.1016/S0014-3057(99)00200-1

7. Mousa A, Heinrich G and Wagenknecht U. Thermoplastic composites based on renewable natural resources: unplasticized PVC/Olive Husk. International Journal of Polymeric Materials. 2010; 59(11):843-853. http://dx.doi.org/10.1080/ 00914037.2010 .504143

8. Mousa A, Heinrich G, Gohs U, Hassler R and Wagenknecht U. Application of renewable agro-waste-based olive pomace on the mechanical and thermal performance of toughened PVC. Polymer - Plastics Technology and Engineering. 2009; 48(10):1030-1040. http://dx.doi. org/10.1080/03602550903092559

9. Mousa A, Heinrich G and Wagenknecht U. Rubber-Wood Composites from Chemically Modified Olive Husk Powder and Carboxylated Nitrile Butadiene Rubber: Cure Characteristics, Tensile Behavior, and Morphological Studies. Journal of Wood Chemistry and Technology. 2012; (32)82-92, 2012. http://dx.doi.org/10.1080/02773813.2011.599469

10. Mousa A, Heinrich G and Wagenknecht U. Cure Characteristics and Mechanical Properties of Carboxylated Nitrile Butadiene Rubber (XNBR) vulcanizate reinforced by Organic Filler. Polymers-Plastics Technology and Engineering. 2011; (50)13:1388-1392. http://dx.doi.org/10.1080/03602559.201 1.584242

11. Hoffmann B, Dietrich C, Thomann R, Friedrich C and Mulhaupt R. Morphology and rheology of polystyrene nanocomposites based upon organoclay. Macromolecular Rapid Communications. 2000; 21(1):57-61. http://dx.doi. org/10.1002/(SICI)1521-3927(20000101)21:1<57:AID-MA RC57>3.0.CO;2-E

12. Reichert P, Nitz H, Klink S, Brandsch R, Thomann R and Mulhaupt R. Poly(propylene)/organoclay nanocomposite formation: Influence of compatibilizer functionality and organoclay modification. Macromolecular Materials and Engineering. 2000; 275(1):8-17. http://dx.doi.org/10.1002/ (SICI)1439-2054(20000201)275:1<8:AID-MAME8>3.0. $\mathrm{CO} ; 2-6$

13. Mousa A and Karger-Kocsis J. Rheological and Thermodynamical Behavior of Styrene/Butadiene Rubber-Organoclay Nanocomposites. Macromolecular Engineering Journal. 2001; 286(4):260-266. http://dx.doi. org/10.1002/1439-2054(20010401)286:4<260:AID-MAME 260>3.0.CO;2-X

14. Teh PL, Mohd Ishak ZA, Hashim AS, Karger-Kocsis J and Ishiaku US. On the potential of organoclay with respect to conventional fillers (carbon black, silica) for epoxidized natural rubber compatibilized natural rubber vulcanizates. Journal of Applied Polymer Science. 2004; 94:2438-2445. http://dx.doi. org/10.1002/app.21188

15. Kotek J, Kelnar I, Studenovsky M and Baldrian J. Chlorosulfonated polypropylene: preparation and its application as a coupling agent in polypropylene-clay nanocomposites. Polymer. 2005; 46(13):4876-4881. http:// dx.doi.org/10.1016/j.polymer.2005.02.119

16. Mousa A, Heinrich G and Wagenknecht U. The Potential of O-MMT as a Reinforcing Filler for Uncured and Dynamically Cured PVC/XNBR Composites. Journal of Macromolecular Science, Part A Pure and Applied Chemistry. 2008; 45(9):733-741. http://dx.doi. org/10.1080/10601320802222632

17. Fowkes FM. Additivity of intermolecular forces at interfaces. I. Determination of the contribution to surface and interfacial tensions of dispersion forces in various liquids. The Journal of Physical Chemistry. 1963; 67(12):2538-41. http://dx.doi. org/10.1021/j100806a008

18. Varghese S and Karger-Kocsis J. Natural rubber-based nanocomposites by latex compounding with layered silicates. Journal of Applied Polymer Science. 2003; (40):4921.

19. Feldman D, Banu D, lora J and El-raghi S. Rigid poly(vinyl chloride)-organosolv lignin blends for applications in building. Journal of Applied Polymer Science. 1996; (61):211-2128. http://dx.doi.org/10.1002/(SICI)1097-4628(19960919)61:12 $<2119:$ :AID-APP10>3.0.CO;2-2

20. Din RH, Musa L, Aziz AA and Tay G-S. Unsaturated polyester-kenaf composites: the effects of a modified montmorillonite filler on the tensile properties. Polymer-Plastics Technology and Engineering. 2010; 49(9):929-937. 